\title{
DOSSIÊ: \\ PARADIGMAS TÉCNICO-ECONÔMICOS E RECONFIGURAÇÃO TERRITORIAL \\ DOSSIER: \\ TECHNO-ECONOMIC PARADIGMS AND TERRITORIAL RECONFIGURATION
}

\author{
Rovena Negreiros \\ Aristides Monteiro Neto* \\ * Instituto de Pesquisa Econômica Aplicada, Ipea, Brasília, DF, Brasil.
}

Este dossiê de estudos e reflexôes sobre mudanças tecnológicas e reverberaçôes territoriais no capitalismo contemporâneo busca chamar atenção para o desempenho da economia brasileira e a inserção do Brasil na economia global diante dessas mudanças, considerando a possibilidade, ou mesmo a capacidade, do país de se reorganizar para adotar uma agenda que favoreça sua inserção provocada pelas mudanças tecnológicas. São, sem dúvida, tempos de transformações tecnológicas e produtivas aceleradas, com rebatimentos territoriais profundos e ainda em curso, alguns deles mesmo em fase de cristalização de sua dimensão e consequências.

A reflexão proposta neste dossiê visa contribuir para uma ampliação das visóes de processos no mais das vezes em curso e não consolidados - em transição, portanto, ou seja, a situação em que o velho não morreu e o novo não se definiu em sua inteireza. Pretende-se aclarar os termos dessa transição, seus elementos característicos, os impactos territoriais e setoriais mais visíveis, assim como os elementos de políticas públicas a ela associados.

A proposta de organização deste projeto "dossiê" para a presente edição da revista da Anpur (REURB) é concretizada mediante três atos ou temporalidades fundamentais. O primeiro ato trata dos propósitos da temática posta para abordagem pelos autores. $\mathrm{O}$ segundo revela a problematização do tema em face do debate nacional, com base nos artigos selecionados para o dossiê. Por fim, o terceiro ato aponta as liçóes aprendidas, com um balanço conclusivo dos enfoques aqui apresentados e a perspectiva de uma nova agenda de pesquisa sobre a temática.

\section{PRIMEIRO ATO - PROPÓSITOS DO DOSSIÊ TEMÁTICO}

Transformaçôes aceleradas na trajetória econômica mundial se tornaram cada vez mais frequentes e intensas nas últimas três décadas. A revolução tecnológica nas comunicaçôes, com impactos aceleradores nos meios de transportes e no sistema financeiro, modificou o modo de tomada de decisão capitalista sobre as formas de investimento em ativos tangíveis e intangíveis. Territórios, setores econômicos, empresas e indivíduos passaram a atuar sobre contínuo escrutínio das informaçóes e avaliaçóes globais, em tempo real, sobre lucros, rendimentos e alternativas de ganho.

A consolidação de um padrão de atividade econômica chamado de tecnoinformacional, fundamentado em tecnologias de informaçáo e comunicação (TICs), solapou modelos de desenvolvimento voltados para a produção de bens primários, intensivos em recursos naturais, e também para a atividade industrial clássica, tradicionalmente intensiva em escala e/ou mão de obra.

A mirada histórica sobre a trajetória das naçôes capitalistas e modernas sempre afirmou que a etapa do desenvolvimento se efetivou pela transição de suas economias de atividades agrícolas ou agropecuárias em direção à produção industrial. Esse foi o caminho percorrido por países da Europa

DOI: https://doi.org/10.22296/2317-1529.2019v21n2p223 
Ocidental, como Inglaterra, França, Alemanha, Itália e Bélgica, e também pelos Estados Unidos e o Japão. O momento presente - que, no entanto, não é tão presente, pois começou, ao menos com mais visibilidade, nos anos 1970 - é de nova e acelerada transição rumo a um processo de redução da participação do setor industrial nas economias desenvolvidas e de concomitante aumento da parcela relacionada com atividades terciárias ou informacionais.

Vale rememorar que o debate sobre transformação estrutural ou reestruturação produtiva ganhou enorme impulso no período posterior à Segunda Guerra Mundial com os estudos, para os países desenvolvidos, dos pioneiros do desenvolvimento: autores como Lewis (1954), Myrdal (1957), Kuznets (1971) e Kaldor (1966, 1970), entre os mais proeminentes, e de Prebisch (1949) e Furtado (1961) para os países latino-americanos. Grosso modo, esses autores se alinharam à visão de que o desenvolvimento nacional deveria se sustentar na transformaçáo de economias baseadas em setores agrícolas, de baixa produtividade média, em economias industrializadas, de mais alta produtividade. Pode-se dizer, alternativamente, que a diversificação produtiva se voltaria à incorporação crescente de setores de densidade de capital e de tecnologia mais elevada. A indústria passou a ser o motor de crescimento das economias nacionais em razão das externalidades positivas geradas pelas economias de escala que lhes são próprias e capazes de gerar impulsos sobre outros setores a montante e a jusante na forma de compra de insumos, equipamentos, máo de obra e serviços.

Diferentemente do que se passa nas economias desenvolvidas, nos países da periferia do capitalismo e que não se industrializaram o suficiente para expandir sua renda/ produto per capita em patamar próximo dos vistos na Europa e nos Estados Unidos, a insurgência de um processo de desindustrialização precoce está se delineando com consequências dramáticas. A renda per capita vem estagnando, juntamente com a capacidade de geração de empregos de altos salários. A competitividade externa de suas economias tem declinado e vários países que enfrentam esse processo, inclusive o Brasil, estão experimentando, segundo alguns especialistas, um processo de transformação estrutural regressiva.

O processo de reestruturação produtiva por que passa a economia nacional, desde pelo menos o início dos anos 1990, sob as formas de desindustrialização e reprimarização setorial, tem sido motivo não somente de extenso escrutínio, como também de controvérsia acadêmica. Estudos como o de Bonelli, Pessoa e Mattos (2013) argumentaram que a desindustrialização brasileira teria a mesma conformidade com os processos similares nas economias desenvolvidas. Isso não se constitui em problema grave, a náo ser pelo fato de que a produtividade geral da economia brasileira permaneceu abaixo dos padrôes internacionais nas últimas duas décadas. $\mathrm{Na}$ contramão dessa visão etapista estão, entre outros, os trabalhos de Cano (2008 e 2012), que alertam para a redução da atividade industrial associada à redução de conteúdo tecnológico da pauta exportadora nacional. Para esse autor, a desindustrialização no Brasil é precoce e ocorre quando a renda per capita nacional se encontra em patamar muito baixo quando comparada com os níveis observados na experiência internacional.

Algumas conclusôes mais definitivas já podem ser salientadas, entretanto, com base em estudos bem mais recentes. Se na experiência dos países desenvolvidos a desindustrializaçáo se manifesta orientada pelo crescimento superior das atividades terciárias como proporção do produto nacional - ou seja, pela alteração dos padróes 
de demanda de seus mercados consumidores em direção a mais e mais serviços e bens de conteúdo informacional e menos de bens industrializados tradicionais -, nas economias dos países em desenvolvimento, como o Brasil, a redução da importância relativa do produto industrial se deve muito mais à perda de competitividade estrutural desse setor que à expansão de suas atividades terciárias.

No Brasil, a desindustrializaçáo corresponde, como apontado por vários pesquisadores, em virtude da redução de sua competitividade consubstanciada em: a) perda de capacidade exportadora acompanhada de forte entrada de componentes importados no processo produtivo (Cano, 2012; Sampaio, 2015; Morceiro, 2016; Sarti e Hiratuka, 2017); b) redução da produtividade média setorial (Galeano e Feijó, 2013; De Negri e Cavalcante, 2014 e 2015; Arend et al, 2016); e c) reespecialização em setores de mais baixa intensidade tecnológica e/ou intensivos em recursos naturais (Sampaio, 2015; Morceiro, 2016; Vital da Costa e Neves, 2016; Monteiro Neto e Silva, 2018).

As mudanças estruturais recentes, em especial as decorrentes da reestruturação da indústria, com perda relativa do produto industrial no total da economia nacional, revelam, não só pela perda de importância nesse movimento das transformações econômicas, o declínio de sua centralidade como, regionalmente, uma desconcentração territorial da indústria a partir de São Paulo para o Sudeste, Sul e CentroOeste, e com menor vigor para as regiōes Norte e Nordeste. A estrutura industrial nos últimos vinte anos, no contexto regional do país, foi marcada pela expansão das indústrias ligadas à base de recursos naturais em todas as macrorregiōes, com exceção do Sul. Já as indústrias de tecnologias diferenciadas e/ou baseadas em ciências, caracterizadas por maior densidade técnica e de conhecimento, apresentaram dificuldades para se expandir em todas as regióes.

Em face desse diagnóstico em consolidação no debate acadêmico, torna-se natural a preocupaçáo com o curso do processo regressivo de reestruturaçâao produtiva e especula-se sobre as possibilidades ainda abertas para a reversão dessa trajetória preocupante. É o que se aponta no texto no sítio da internet da Anpur, no qual se fez o convite à chamada de trabalhos para este dossiê: "No momento presente, indagase, se a economia nacional, será capaz de incorporar esse novo padrão tecnológico, onde a nova indústria poderá ou náo promover um novo ciclo de desenvolvimento econômico para o país, e quais os impactos que ela poderá produzir sobre as cidades e os cidadãos? Nesse ciclo, quais tendem a ser os rebatimentos territoriais das atividades produtivas?".

Tais questôes remetem à reflexão de que está em jogo a possibilidade de o país ainda ser capaz de conter ou reverter sua trajetória de declínio da produção e competitividade de seus setores industriais mais relevantes, como as implicaçôes territoriais - regionais, metropolitanas, da rede de cidades e ambientais - sobre o quadro prevalecente de disparidades socioeconômicas, os quais configuram inquietaçôes para o debate de políticas de desenvolvimento. Não por outra razão se questionou, a título de provocação geral, no convite à chamada: "Que sentido adquirem as disparidades inter-regionais num cenário de forças instáveis e pouco previsíveis?” como as que efetivamente preponderam no cenário atual.

Tendo em pauta a vertente da dinâmica econômica regional brasileira, verificou-se que, a partir de meados da década de 2000, se consolidaram três vetores de desenvolvimento territorial mais evidentes. Um deles derivou da descoberta dos campos do pré-sal 
no litoral dos estados do Rio de Janeiro, São Paulo e Espírito Santo, o qual contou com a determinação do governo federal para que a Petrobras ocupasse uma posiçáo de primazia na organização de um ciclo de investimentos capaz de assegurar um papel de relevo para o país no mercado internacional de petróleo. Dados os elevados recursos de investimento previstos e o estímulo para a expansão de cadeias produtivas ligadas ao petróleo (química, petroquímica, bens de capital etc.), esse vetor de expansão da economia brasileira continha todos os elementos para promover uma nova reconcentração do Produto Interno Bruto (PIB) em favor da região mais rica do país, o Sudeste.

O segundo vetor de desenvolvimento territorial é relativo à expansão da demanda internacional por commodities agrícolas e de carnes do Centro-Oeste do país e que, de fato, contribuiu para acelerar a participação dessa regiáo na economia brasileira e, portanto, para promover a desconcentração produtiva regional.

Por fim, o terceiro vetor está relacionado com os esforços da política de investimento de infraestrutura, estimulada em nível federal, nas regiôes Norte e Nordeste - como as hidrelétricas de Belo Monte (PA), Santo Antônio e Jirau (RO), a Ferrovia Transnordestina e obras da transposição do rio São Francisco - por meio da expansão de recursos da política regional (os fundos constitucionais). Essas políticas, por sua vez, foram muito potencializadas pelas políticas sociais e de transferência de renda a pessoas pobres, as quais tiveram impacto sobre a redução da pobreza, da desigualdade e da expansão da renda e produto generalizado nessas regiốes do país. Como se pode ver, estabeleceram-se vetores de expansão econômica no território com direçóes contrárias, favorecendo ora a desconcentração, ora a reconcentração.

A política econômica vigente no período 2003-2015 imprimiu marcas sobre o território brasileiro que precisam ser trazidas à luz neste momento. Foram esforços que, se nem sempre foram capazes de reverter trajetórias indesejáveis e consolidadas na estrutura produtiva nacional, tiveram, contudo, rebatimentos territoriais que devem integrar o quadro explicativo das transformaçóes econômicas prevalecentes.

Vale demarcar que a política federal de valorização do salário mínimo, aumentando a renda real de amplas camadas da população brasileira (classes C e D); as políticas de transferência de renda a famílias em extrema pobreza, como o Programa Bolsa Família, aposentadorias rurais e os Benefícios de Prestação Continuada (BPC); a expansão do crédito público federal para o setor de habitação, movimentando diretamente a construçáo civil e toda a cadeia a ela associada; ainda a expansão do crédito público para as atividades terciárias, agrícolas e industriais, casos do Banco do Brasil, BNDES e bancos regionais de desenvolvimento, como o Banco do Nordeste (BNB) e Banco da Amazônia (Basa); e, por fim, a ampliaçáo do investimento público federal em infraestrutura de transportes e energética, gerador de externalidades positivas para empreendimentos privados em regióes beneficiadas.

Tais esforços - de resto, já bastante analisados pela literatura acadêmica especializada - resultaram em movimentação da atividade produtiva associada a bens de consumo não durável e intermediário demandados pelo impulso da expansão da renda e do emprego das classes de renda mais baixas da população. Os ramos de atividades mais tradicionais já presentes na estrutura produtiva nacional é que foram beneficiados pelos maiores impulsos ao crescimento.

Em outra vertente do impulso ao crescimento econômico e à reestruturação produtiva, destaca-se a expansão da demanda internacional por commodities agrícolas, de carnes e minerais com impactos significativos sobre a agricultura das regiôes 
Centro-Oeste, Sudeste e Sul. Com estímulos de mercado a uma reespecialização em atividades primárias, a economia brasileira passa a crescer mais em função da expansão da renda externa e menos baseada em forças dinâmicas internas. A pauta exportadora nacional, que até meados dos anos 1990 era mais de produtos industriais em detrimento dos agrícola-minerais, mudou sua composição nos anos recentes com forte diminuiçâo da parcela dos bens industriais e/ou de alto valor agregado. Na verdade, a estrutura industrial tem se tornado fortemente importadora de insumos e bens intermediários com redução do componente interno de geração de valor agregado, como vários estudos têm comprovado (Cano, Sampaio).

Um conjunto rico e variado de fenômenos econômico-territoriais está em curso presentemente no país. Sua evolução futura contém, entretanto, fortes doses de indeterminação quanto à trajetória das disparidades produtivas. O país se aproximará do vetor de reconcentração associado a uma possível retomada da força da indústria em sua regiáo mais desenvolvida? Ou, contrariamente, os vetores de desconcentração predominarão ao custo da reprimarização produtiva e do estabelecimento de baixa produtividade na atividade industrial das regióes-alvo de políticas regionais?

O presente dossiê foi pensado, justamente, para fortalecer o debate por meio do questionamento de paradigmas prevalecentes e do estímulo à proposição de novos olhares, reflexôes e abordagens teóricas sobre o conhecimento existente. Neste sentido, algumas questốes orientadoras, embora não limitadoras, foram sugeridas como provocação:

- O que se pode afirmar sobre o estágio atual do desenvolvimento brasileiro, suas possibilidades e limitações para a consolidação do paradigma tecnoinformacional no país (e em suas regióes)?

- Em face da reestruturação produtiva em curso, que sentidos e direçóes podem ser percebidos para a reorganização territorial e para as disparidades regionais?

- Qual é o novo mapa da indústria no Brasil?

- Reestruturação ou desindustrialização: quais impactos e implicaçóes territoriais no país?

- Como anda a distribuição regional da estrutura econômica do país?

- Quais os impactos do chamado boom das commodities (agrícolas e minerais) na configuração das diferentes economias regionais?

- O ciclo de crescimento recente (2000-2015) brasileiro aponta para ressignificaçóes nas redes de cidades?

- Neste contexto de reconfiguraçôes produtivas, o Brasil atlântico da urbanização costeira continua a ser o território preferencial dos fluxos econômicos e populacionais? Que novidades demográficas surgiram?

- Como (re)orientar políticas produtivas e regionais, isto é, o planejamento governamental, no contexto atual, para uma nova trajetória de desenvolvimento?

\section{SEGUNDO ATO - DIÁlOGO DOS ARTIGOS COM O DEBATE DO DESENVOLVIMENTO ECONÔMICO E REGIONAL BRASILEIRO}

Um primeiro grupo de artigos percorre uma análise a partir das mudanças tecnológicas em curso e seus rebatimentos na economia brasileira e regional. Também se 
apresenta um balanço das transformaçóes econômicas do período 2000-2015 na economia brasileira ditadas pelas mudanças produtivas e seus impactos regionais.

O artigo "Corrida científica e tecnológica e reestruturação produtiva: impactos geoeconômicos e geopolíticos”, de Clélio Campolina Diniz (Cedeplar/UFMG), contribui de modo significativo para uma leitura do desenvolvimento como uma estratégia de mudança estrutural no capitalismo contemporâneo. $\mathrm{O}$ autor reconhece a emergência de uma nova geoeconomia em que países da Ásia (China, Coreia do Sul e Índia), cujo esforço de desenvolvimento tecnológico nos ramos de atividades industriais tem sido elevado, passam a responder por parcela expressiva do produto total, do produto industrial e das exportaçôes industriais do mundo. Na outra ponta, países da Europa, além de Estados Unidos e Japão, perderam participação relativa na economia mundial.

Neste quadro de reposicionamento dos países na economia mundial, a corrida científica e tecnológica (p. 241) tornou-se um elemento de centralidade na busca pela proeminência tecnológica. De maneira crescente, os países desenvolvidos intensificam o gasto e o esforço estratégico na criação e na consolidação de setores intensivos em conhecimento e tecnologia. Para o Brasil, esse quadro internacional, segundo o autor, se mostra bem desafiador: de um lado, está em curso um processo de desindustrialização precoce associado à perda de competitividade externa de sua estrutura produtiva e, de outro, o gasto em $\mathrm{P} \& \mathrm{D}$, que representa o esforço de realizaçáo da inovaçáo, tem sido efetivado mais pelo governo do que pelo setor privado nacional. As implicaçóes territoriais são abordadas no artigo, no qual se enfatizam as dificuldades enfrentadas pelas regiôes menos desenvolvidas - em particular, a regiáo Nordeste, mais populosa e com carências socioeconômicas mais pronunciadas - para se adaptarem a esse contexto de grandes aceleraçóes tecnológicas.

O autor receia que, no Brasil, a questáo regional depare novamente com uma trajetória de reconcentração econômica em suas regióes mais desenvolvidas e mais capazes de atrair os setores tecnologicamente mais avançados: "Como a maior densidade econômica e a infraestrutura de ciência e tecnologia está predominantemente localizada nas regióes Sudeste e Sul do Brasil, os possíveis impactos da reestruturação produtiva poderão afetar o processo de desconcentração econômica e industrial no país, especialmente para o Nordeste, região populosa e economicamente mais atrasada” (p. 254). O essencial dessa discussão de Diniz reside em sua atenção às mudanças no paradigma tecnoeconômico em escala global e às formas com as quais os países passaram a lidar para manter e/ou conquistar posiçóes superiores na corrida científica e tecnológica. A leitura sobre o posicionamento do Brasil diante dessa corrida - retardatário e inconstante - e seus possíveis rebatimentos territoriais - com tendência, segundo ele, ao aumento das disparidades regionais - devem ser assimilados com um alerta importante endereçado às políticas de desenvolvimento do país nos dias atuais.

Particularizando o contexto nacional do desenvolvimento regional e buscando fazer um balanço das transformaçóes ocorridas durante o período 2000-2015, têm-se os artigos "Mudanças produtivas e econômicas e reconfiguração territorial no Brasil no início do século XXI", de Carlos Brandão (Ippur/UFRJ) e "A desconcentração produtiva entre 2000 e 2015: uma nova dinâmica virtuosa?”, de Sílvio Moraes e Marília Steinberger (pesquisadores da UnB). Suas análises contribuem para a reflexão, no primeiro caso, das transformaçóes produtivas e territoriais geradas como resul- 
tado do estabelecimento de vetores de políticas públicas (macroeconômicas, sociais e de infraestrutura) no período novo-desenvolvimentista por que passou o país. No segundo caso, a análise sugere que, ao contrário do esperado, "a conjunção de fatores, como a reorientação político-institucional, o ciclo de crescimento econômico e o contexto internacional favorável, dentre outros, propiciou o surgimento de uma nova dinâmica virtuosa da desconcentração produtiva no período entre 2000 e 2015 ”.

Vejamos mais detidamente aspectos salientes de cada um dos estudos acima mencionados. Brandão informa que as mudanças territoriais vistas no período 2000-2015 são significativamente determinadas pela reconfiguração do capitalismo neoliberal desde a década anterior: "Assim, ao longo dos anos 1990, as mudanças na paisagem regional brasileira resultaram, em grande medida, de involuçôes e desconstruçôes, isto é, foram consequências mais dos impactos regionalmente diferenciados da crise econômica e das opçôes conservadoras de políticas macroeconômicas do que de processos reestruturantes" (p. 263). Na fase seguinte, pós-2000, o contexto externo benigno para as exportaçóes brasileiras de commodities permitiu certa folga para a condução de políticas de crédito e de infraestruturas propiciadoras de desconcentração produtiva regional. Comenta o autor: "Mesmo que não orientada por uma clara estratégia industrial, já que as decisóes privadas e pública pouco ou nada se orientaram pelo Plano Brasil Maior, a geografia econômica brasileira passou por mudanças importantes, sobretudo no decênio 2004-2014. Vultosas inversóes de capitais privados, com forte apoio estatal, em especial do BNDES, ocorreram nos setores agroindustriais, na indústria extrativa mineral, na indústria automobilística e de infraestrutura. De fato, gigantescos investimentos estavam em andamento em plantas automobilísticas, siderúrgicas, de petróleo, naval, nas refinarias, extração mineral etc." (p. 266). Com tantas e tấo diversificadas inversóes produtivas, os impactos territoriais de sua aplicação ainda carecem de uma avaliação mais qualificada, capaz de promover a compreensão de que as estruturas produtivas e tecnológicas se orientaram para que partes do território nacional? De modo inovador, Brandão sugeriu uma tipologia de territórios impactados por orientaçóes, de um lado, das forças de mercado - ora internas, ora externas - atuantes no país e, de outro, dos vetores de gasto e investimento governamentais planejados pela política pública. Essa tipologia propóe, em caráter exploratório, a investigação de cinco territórios específicos, os quais poderiam dar conta das dinâmicas econômicas mais representativas sobre o território nacional no período.

Ao sugerir recortes territoriais, o texto aponta para significativas alteraçóes em curso no mapa da questão regional brasileira. Notadamente, o desempenho da economia centro-oestina por força dos estímulos das commodities exportáveis e, secundariamente, os impactos - ainda em curso - de macroempreendimentos como o pré-sal (no Sudeste), a Transnordestina e a transposição do rio Sáo Francisco (no Nordeste), entre outros. Ao lado da preocupaçáo em vislumbrar novas possibilidades em favor da trajetória de desconcentração produtiva regional no país, o autor traz luz ao debate sobre a força e a direçáo do planejamento governamental com o propósito de alterar dinâmicas territoriais consolidadas.

Por sua vez, a contribuiçấo realizada por Moraes e Steinberger (Geografia/UnB) para esta coletânea tem um relevante aspecto metodológico de interesse para os estudos sobre a desconcentração regional no país. $\mathrm{O}$ referido trabalho dialoga diretamente com, ao menos, duas teses centrais do debate regional recente: primeiro com a abordagem de Cano (1985) e Diniz (1993) sobre a concentração preferencial no 
Sul-Sudeste e, também, com a de Pacheco (1998) sobre a fragmentação do mercado interno nacional. Os autores lançam duas perguntas: a desconcentração produtiva continua em curso no país no período recente de 2000-2015? E, se de fato existe, qual forma mais característica ela assume agora? Dois recortes territoriais foram percorridos para obter os elementos para a formulaçáo de uma resposta: as escalas interestadual e intraestadual da desconcentração produtiva.

Avaliando os dados de taxas de crescimento e de participação relativa dos PIBs estaduais, os autores constataram a viabilização de um processo de convergência dos PIBs estaduais entre 2002 e 2015 pelas taxas mais elevadas de crescimento em economias estaduais de pequeno tamanho e localizadas em regióes de baixo desenvolvimento, isto é, com elevado crescimento acumulado do PIB. Em ordem decrescente, têm-se os estados de Tocantins, Mato Grosso, Piauí, Acre, Rondônia, Roraima, Maranhão, Amapá, Mato Grosso do Sul e Amazonas. Eles também demonstraram que as cinco economias estaduais mais relevantes (São Paulo, Rio de Janeiro, Minas Gerais, Rio Grande do Sul e Paraná) detinham 64,7\% do PIB nacional em 2002, porcentagem que caiu para $61,2 \%$ em 2015 . Por outro lado, os demais 22 estados passaram de 31,9\%, em 2002, para 35,3\% em 2015. Portanto, o crescimento econômico estaria ocorrendo em estados situados fora da área preferencial do Sul-Sudeste: "Dessa forma, pode-se inferir que o maior dinamismo econômico dos anos 2000, ao menos até a eclosão da recente recessão subsequente a 2014, não apenas assinala o avanço de um momento mais virtuoso da desconcentração produtiva, como também parece ter refreado parte das preocupaçôes reais acerca de uma retomada da polarizaçấo produtiva no Sudeste brasileiro, especialmente em Sáo Paulo” (Moraes e Steinberger, p.287).

A segunda tese parte da investigação da existência de uma trajetória de fragmentaçáo do mercado nacional, em que a fragilização do Estado e a abertura produtivofinanceira da economia brasileira, nos termos colocados por Pacheco (1998), deveriam redundar na perda dos elos do mercado interno. Neste contexto de relaçôes globalizadas, Pacheco sugere que as economias regionais brasileiras passariam a estar mais ligadas ao comércio mundial que ao mercado nacional.

Moraes e Steinberger organizam sua intervenção no debate mediante a avaliação de trajetórias regionais em curso com vistas a identificar processos na escala estadual de interiorização do desenvolvimento e de desconcentração produtiva. De acordo com os autores, se existirem evidências de interiorizaçáo do desenvolvimento, então, os governos estaduais estariam, ao seu modo, conseguindo imprimir trajetórias de crescimento em seus territórios, de sorte que a ação planejadora governamental não teria sido inteiramente perdida. Neste caso, a tese de Pacheco náo se confirmaria, ao menos em sua plenitude. No estudo, os autores verificaram que, no período entre 2000 e 2015, tais trajetórias foram consideradas benignas em estudos acadêmicos sobre as economias estaduais do Ceará, Goiás, Pará e Paraná, onde se observam a expansão e a consolidação de polos produtivos fora das regiōes metropolitanas ou capitais dos estados. Contudo, é feito o alerta de que, em outras experiências estaduais, como daquelas verificadas na Bahia, em Pernambuco e no Rio Grande do Sul, por motivaçóes diversas, as áreas metropolitanas persistem como territórios fortemente polarizadores dentro dos respectivos estados. A despeito dos resultados náo favoráveis à desconcentração territorial nestes últimos estados da federação, a situação geral no país não é de reconcentração exacerbada das atividades econômicas em regióes metropolitanas e capitais consolidadas. Foi o que os levou a fazer a seguinte indagação: "Teria essa nova 
dinâmica da desconcentração nos anos 2000 de fato contido os fantasmas dos anos 1990, os quais apontavam para os riscos de uma eminente repolarização produtiva no Sudeste brasileiro e para uma fragmentação e reprimarização evidentes da economia nacional?" (p. 293).

$\mathrm{O}$ artigo "As exportaçóes industriais regionais brasileiras: análise espacial da primeira década de 2000”, de Daniela Schettini (IRI/USP), propóe uma reflexão sobre a configuração espacial das exportaçôes industriais ao discutir o papel das aglomerações nas exportações industriais dos municípios brasileiros, buscando indicações sobre a competitividade das regiôes e seu impacto no desenvolvimento econômico.

Reafirma-se no artigo que as exportaçôes industriais são bastante desiguais regionalmente, com forte concentração na porção centro-sul do país, com alguns deslocamentos para o centro-oeste. Ao utilizar metodologia de análise exploratória espacial e modelo probit, estimou-se a influência de aglomeraçóes sobre a probabilidade de se exportar. As conclusóes derivadas do método adotado indicam que as aglomeraçóes aumentam a probabilidade de uma regiáo exportar.

A concentração setorial também é elevada na pauta exportadora e ocorre especialmente entre os produtos ligados ao beneficiamento das atividades primárias. Assim, entre os setores com maior potencial de crescimento das exportaçóes estão os de maior conteúdo tecnológico, como máquinas, materiais elétricos e eletrônicos, equipamentos de comunicação e informática, acentuadamente concentrados no centro-sul do país.

Verifica-se que, dadas as disparidades regionais, os demais estados que ainda venham a exportar não usufruem das externalidades positivas geradas nessas aglomeraçôes, tornando mais árdua a atividade exportadora.

Ao procurar avaliar a competitividade das regióes do país e os impactos sobre o desenvolvimento econômico, além de uma possível tendência de convergência e disparidades regionais, destaca-se no texto que, "Se exportar é uma fonte de crescimento da produtividade e estimula o crescimento econômico, deve ser alvo de políticas que visem o incentivo à entrada e/ou permanência das firmas no mercado internacional." (p. 299).

Um segundo grupo de artigos aborda dinâmicas sub-regionais específicas, ou seja, as transformaçóes ocorridas no Sudeste com a consolidação de novos eixos de desenvolvimento territorial. Destacam-se os casos particulares do agronegócio canavieiro em São Paulo e do complexo da petroquímica no Rio de Janeiro, assim como da expansão de commodities na rede de cidades no Centro-Oeste.

As duas contribuições de artigos sobre a economia paulista devem instigar a reflexão das transformaçôes em curso naquela que é a principal economia estadual brasileira e que foi o núcleo dinâmico do processo secular de industrialização do país entre 1870 e 1980. Passando por uma etapa de desindustrialização acelerada, associada ao fortalecimento dos setores financeiro e do complexo agroindustrial, quais são, de fato, as formas produtivas que se consolidam nesse estado em períodos recentes? E mais, dado o seu peso relativo na economia nacional, que implicaçóes para o desenvolvimento regional podem ser vislumbradas com a da reestruturação produtiva paulista atual?

$\mathrm{O}$ artigo "Reestruturação produtiva e consolidação de novos eixos de desenvolvimento territorial: o caso do vetor de desenvolvimento perimetral da macrometrópole paulista”, de Anderson Dias de Almeida Proença e Wilson Ribeiro dos Santos Jr. (PUC-Campinas), revela a mudança de estratégia de planejamento territorial do estado de Sáo Paulo ao abandonar a concepção de polos de desenvolvimento industrial, substituindo-os pela ideia de vetores de desenvolvimento inter-regional ou 
"regionalização unificadora-complexa", cujo território, para efeitos de planejamento, é contemporaneamente conhecido como a "macrometrópole paulista" (MMP).

$\mathrm{Na}$ visão dos autores, essa nova concepção do planejamento territorial ampliou as assimetrias regionais entre as áreas metropolitanas e não metropolitanas do estado de São Paulo. A MMP, estruturada em um sistema de fluxos econômicos com um sistema de serviços organizados em rede, viabilizada por importantes infraestruturas de circulação, engendrou uma organização espacial da rede urbana que a compóe. Esse território expressa um nível de concentração sem precedentes, ao representar $83 \%$ do PIB e 74\% da população do estado, em 2010.

A consolidação desse vetor decorre do grande volume de investimento em infraestrutura de transporte inter-regional capaz de proporcionar condiçóes de atraçáo e localizaçâo dos segmentos modernos da indústria contemporânea. Resultou na configuração de um corredor produtivo, com reorganizaçáo da geografia das estruturas produtivas, das redes de logística e da ocupaçáo urbana. Nesse território expandido concentram-se os setores produtivos mais modernos e de maior produtividade. Verifica-se o predomínio de atividades econômicas baseadas em conhecimento e em informaçóes tecnocientíficas, resultante do poder atrativo gerado por sua mais elevada densidade de infraestrutura tecnológica.

Nessa reorganização territorial na MMP, identifica-se um novo vetor de desenvolvimento perimetral, com perspectivas de consolidação de um eixo tecnológico, o qual vem se qualificando para intensificar as articulaçôes econômico-produtivas em direção às regiôes metropolitanas imediatamente circunvizinhas de Sorocaba, Campinas e São José dos Campos. Sua força vital passa a se constituir em significativos montantes de investimento em ramos da nova economia, os quais, cada vez mais, demandam condiçóes de suporte específico com relação à infraestrutura de transporte e de comunicação, bem como à geração de conhecimento e elevada qualificaçáo de mão de obra.

O texto em foco contribui, na verdade, para a compreensão da mudança estratégica de planejamento em nível estadual, segundo a qual a aposta do crescimento da economia paulista deve estar ancorada em setores produtivos ligados à economia do conhecimento, por sua vez localizada em uma grande mancha urbana que vai além da metrópole paulista (a Região Metropolitana de São Paulo, RMSP) e se articula com outras RMs circunvizinhas, igualmente dotadas (e interligadas) de ampla infraestrutura de transportes, de conexôes de comunicaçóes e, principalmente, de ativos de conhecimento representados pelo sistema de ensino e pesquisa mais desenvolvido do país. Essa estratégia de planejamento - o território da macrometrópole paulista responderia, desse modo, à reversão do processo de desindustrialização da RMSP e criaria o ambiente para a reestruturação produtiva em bases consequentes com as necessidades de ingressar no novo paradigma produtivo das tecnologias de informação e conhecimento (TICs).

Em nosso entendimento, o alerta dos autores é de que o recorte territorial para efeitos de planejamento, ao privilegiar uma porção mais representativa da economia estadual paulista e destinar estratégias de investimentos infraestruturais e de conhecimento, tenderá a acirrar as disparidades econômicas dentro do próprio estado.

O enfoque do papel do agronegócio canavieiro em São Paulo é apresentado no artigo "Hierarquias regionais no agronegócio canavieiro: movimento da fronteira e a centralidade de São Paulo", de Fernando Campos Mesquita, Ricardo Castillo, Ivette Luna e Henrique Farias Santos (UNICAMP). Nele, destacam-se os diferentes papéis 
de comando que o agronegócio canavieiro de São Paulo representa no setor sucroenergético na dinâmica da fronteira agrícola em direção ao Centro-Oeste, nos anos posteriores a 2000, com impactos sobretudo na rede de cidades que se formam ao sul de Goiás, leste de Mato Grosso do Sul e Triângulo Mineiro.

$\mathrm{O}$ artigo revela como tais impactos vêm acentuando hierarquias entre as regióes canavieiras em decorrência do comando político e técnico da produção de São Paulo, ditado pela sede dos grupos das grandes empresas do setor, que centralizam nesse estado as decisões que afetam as Unidades Agroindustriais Sucroenergéticas integrantes do setor e localizadas fora do território paulista. Também se enfatiza que a geração de conhecimento técnico é essencial à produção industrial e agrícola nesse segmento. Os impactos mencionados evidenciam como o conhecimento técnico mais complexo e as decisóes estratégicas constituem novos vetores das desigualdades regionais no país.

O principal argumento do artigo está nas relaçôes de poder e produçáo do conhecimento com impactos nas desigualdades regionais, que, portanto, "não estão restritas à distribuição das atividades produtivas, elas envolvem a forma como ativos intangíveis do conhecimento útil ao processo de inovação e relaçóes de poder se organizam no território" (p. 331) e acabam por resultar num movimento heterogêneo e hierárquico.

De acordo com o artigo, se a metrópole de Sáo Paulo perde centralidade na produção em termos relativos, ganha em centralidade política e tecnológica. Com isso, sua importância no setor tem aumentado à medida que qualifica sua posição na divisão territorial do trabalho.

O complexo petroquímico no desenvolvimento do Rio de Janeiro é analisado no artigo "Boom, Burst e Doom: o complexo petroquímico do estado do Rio de Janeiro como alavanca do desenvolvimento urbano-regional", de autoria de Robson Dias da Silva (UFRRJ) e Clara Irazabal Zurita (University of Missouri). No texto discute-se o desenvolvimento regional, no contexto periférico da Regiáo Metropolitana do Rio de Janeiro, a partir de investimentos em atividades derivadas de recursos naturais, no Complexo Petroquímico do Estado do Rio de Janeiro (Comperj), que se constituiu como o maior investimento individual da história da Petrobras.

São abordados os efeitos sobre a estrutura produtiva na escala subnacional, considerando aspectos da economia regional e urbana. Ressalta-se que esse investimento se configurou como uma perspectiva de diversificação produtiva com adensamento urbano, propiciada pelas mudanças no marco regulatório e pela descoberta de grandes reservas de petróleo, quando entáo se vislumbrou uma perspectiva de transformaçáo do cenário de produção doméstica.

Apesar da importância do Comperj como vetor de desenvolvimento regional, em razão dos diferentes motivos apresentados ao longo do texto, o Complexo não foi capaz de promover e recuperar o atraso social e econômico da regiáo. Na verdade, ele acabou por revelar um desalento regional.

A análise parte do papel do Comperj como uma estratégia de adensamento da matriz produtiva brasileira, do rompimento da estagnaçáo econômica e de perspectiva de melhorias sociais, como efeito do maior alcance dos potenciais da indústria do petróleo. (p. 353). Essa reflexão destaca os limites e os desafios da industrialização puxada por megaprojetos em regióes periféricas e evidencia a necessidade de refletir mais profundamente sobre o papel da grande indústria como vetor de desenvolvimento em espaços metropolitanos periféricos e economicamente deprimidos.

Por fim, um terceiro grupo de artigos aborda novos setores baseados em conhe- 
cimento e seus impactos. Nesse bloco, um primeiro artigo, intitulado "Network alignment in a catching-up region: towards a new metrics to assess the effectiveness of technology policy", de Janaina Oliveira Pamplona da Costa (IG/UNICAMP), analisa o potencial das redes (networks) entre agentes econômicos na difusão de conhecimento e na produçáo de inovaçóes. Mais precisamente, procura identificar a influência da governança das redes, em nível regional, sobre a eficácia das políticas públicas de tecnologia para promover inovação.

Para tanto, realizou-se uma pesquisa na rede de agentes de inovação em softwares em Recife, Pernambuco. Na amostra de 47 entrevistas, a pesquisa se restringe a 17 empresas de software de Recife de diferentes idades, tamanhos e atividades de produçáo. Conforme se afirma nesse estudo, a escolha da indústria de software limita a generalização dos resultados da pesquisa. No entanto, no que concerne ao espaço amostral, obtiveram-se algumas conclusões.

Segundo a análise realizada, valendo-se de metodologia própria descrita no artigo, as interaçôes formais da rede entre os agentes inovadores na área de software de Recife encontram-se ainda em nível de difusão intermediário, visto que algumas sub-redes não estão tão desenvolvidas e os laços entre os agentes dessa rede se restringem à capital pernambucana, sem articulação para fora. Embora a sub-rede (subnetwork) de negócios tenha sido classificada como consistente, as sub-redes relacionadas a habilidades e tecnologias revelaram possuir consistência intermediária; por outro lado, a sub-rede de financiamento foi classificada como inconsistente.

No ambiente pesquisado, os principais atores locais, interessados em apoiar o desenvolvimento e o crescimento das empresas de software locais, mostraram-se ativos na rede e revelaram a existência de padróes de endogenia: fechada, com laços sobretudo entre agentes da própria regiáo (intrarregionais).

O trabalho revela que o número absoluto de inovaçóes produzidas pelas empresas estudadas é consideravelmente grande para uma região cuja indústria de software é relativamente nova. Contudo, poucas dessas inovaçóes estão na fronteira tecnológica. Apenas uma das empresas entrevistadas introduziu inovaçóes para o mundo. A maioria das inovaçóes era nova apenas na empresa, e não uma inovação fundamental, o que, de acordo com o estudo, sugere a adesão a uma estratégia de imitação. Outra interpretação sugerida é de que, em razão de muitas dessas empresas inovadoras serem pequenas, suas estratégias de inovação se baseariam na resposta às demandas dos clientes, as quais não envolvem inovaçóes radicais. Por fim, concluiu-se que o desenvolvimento de redes locais aumentou a eficácia de políticas direcionadas a melhorar o desempenho local da inovação.

$\mathrm{O}$ artigo de Janaina Oliveira tem o grande mérito de sugerir uma estrutura de avaliação do desempenho ora para o arranjo produtivo, ora para as empresas individualmente e assim contribui para a reflexão acerca dos modos como a política pública poderia orientar melhor sua capacidade de estímulo sobre sistemas empresariais intensivos em conhecimento. É sabida a dificuldade que bancos públicos regionais, orientados para o desenvolvimento regional, têm em acolher pleitos de crédito de empresas de software e tecnologias de informação. Tal situação precisa ser reconsiderada em face das necessidades de revitalização da estrutura produtiva regional no país.

No artigo "A reconfiguraçấo espacial do segmento de call center no Brasil vista a partir da instalaçáo de centrais de teleatividade na Paraíba", escrito por Roberto Veras de Oliveira e Ana Carmen Navarro de Moraes (UFPB), os dados utilizados 
para análise revelam a trajetória de reconfiguração territorial na última década para o segmento de call center, com maior peso para o Nordeste do país.

O texto aponta que os processos de relocalização espacial das centrais de teleatividade no Brasil ocorreram em decorrência da busca de menores custos da força de trabalho e de incentivos governamentais, em um processo de transferência/ampliação de unidades de call centers para cidades de menor porte e regióes periféricas, destacadamente na região Nordeste.

Os resultados da análise indicam que, a despeito de esse segmento representar $30 \%$ do total de vínculos ativos de operadores de telemarketing em estabelecimentos com mil ou mais empregados, as sedes das empresas e os centros decisórios permaneceram localizados no Sudeste. Esse resultado é ratificado pelo papel do poder público ao captar investimentos geradores de emprego formal diante da oferta de tipos variados de incentivos fiscais e territoriais.

Em função dos avanços de novos instrumentos tecnológicos de interação, tais como Digital-to-Analog Converter (DAC), Customer Relationship Management (CRM), Voice over Internet Protocol (VoIP), vigilância de dados, análises de web e de texto, chat robotizados, redes sociais etc., surge uma nova oportunidade a partir de 2016, dada pela perspectiva de que as empresas de call center no Nordeste seguiram investindo e implantando inovações tecnológicas.

Nos últimos anos, as empresas ali instaladas vêm sinalizando que já atingiram seu pico de expansão no formato atual, adentrando uma nova fase, marcada pelo uso da inteligência artificial (robotização) e da disseminação de aplicativos de autoatendimento. Portanto, não se trataria do "fim" dos call centers, uma vez que as empresas trabalham com planos de expansão até 2020, direcionando o investimento tecnológico, com o objetivo de incorporar as inovaçôes tecnológicas para seus clientes empresariais.

\section{TERCEIRO ATO - LIÇÕES APRENDIDAS E TEMAS SUGERIDOS PARA PESQUISA}

Os textos reunidos neste dossiê trazem contribuiçóes peculiares ao debate sobre as transformaçóes produtivas e tecnológicas que estão ocorrendo no país: desde uma mirada mais ampla e panorâmica sobre o desenvolvimento capitalista no mundo - o artigo de Diniz -, passando pelas reflexóes sobre as mudanças territoriais recentes no país oferecidas por Brandão e Moraes e Steinberger, até a análise do potencial exportador brasileiro apresentada por Schettini. No conjunto, contribuem para posicionar as incontornáveis dificuldades do ajustamento da economia nacional às transiçóes tecnoprodutivas em curso na economia global. Alertam para o fato de que a trajetória regressiva de reestruturação produtiva, depois de quase duas décadas de aparecimento, se tornou um elemento permanente do desenvolvimento recente. Não é, portanto, fase passageira nem de fácil superação. Requer esforços de planejamento e arregimentação de instrumentos e recursos numa perspectiva de médio e longo prazos.

$\mathrm{Na}$ outra ponta da mirada, de recorte territorial e/ou setorial mais estrito, os artigos subsequentes apontam para o fato de que são inúmeras as novas experimentaçôes produtivas, de intervenção de planejamento e de apostas em vetores tecnológicos. Contudo, são experiências que, regra geral, demoram a lograr êxito, apresentam escala 
acanhada e reduzida para se expandir e/ou permanecem como tentativas apequenadas daquilo que o interesse nacional estratégico deveria/poderia estimular.

Indo além do conteúdo apresentado pelo acervo de estudos reunidos neste dossiê, entendemos a necessidade de instigar o leitor, nesta oportunidade, no que diz respeito a alguns elementos de consenso, assim como fendas e fissuras do conhecimento sobre o tema proposto, com desdobramentos futuros necessários por parte da comunidade acadêmica.

De um lado, entendemos que há elementos consistentes para um consenso sobre as transformações produtivas no país, os quais deveriam ser razoavelmente assumidos e que estáo em par com as contribuiçôes de pesquisa contidas neste documento. Trata-se dos elencados a seguir.

- As evidências tendem a dar suporte à existência de um processo de desindustrialização precoce com perda de competitividade internacional. De um lado, constata-se que a complexidade da estrutura produtiva industrial tem diminuído, na direção oposta ao que se espera de uma estratégia de desenvolvimento com ampliação da renda per capita e de participação do país no comércio internacional, quer essa complexidade seja vista, por exemplo, por uma abordagem do tipo da complexidade econômica (Gala, 2017) ou por meio do cálculo do índice de densidade produtiva (VTI/VBPI) (Monteiro Neto e Silva, 2018), quer por meio de padrôes de interdependência setorial (análise insumo-produto) (Vital da Costa e Neves, 2016), ou, ainda, por meio do gap ou distância entre a demanda total setorial e a produção total (Morceiro, 2016). De outro lado, a redução da complexidade industrial brasileira também se verifica em diferentes recortes setoriais investigados, seja usando a tipologia de "fator competitivo", em que os grupos industriais são organizados em "baseados em recursos naturais, baseados em máo de obra, intensivos em escala, diferenciados e intensivos em conhecimento" (Monteiro Neto e Silva, 2018); seja por "intensidade tecnológica" (como fazem Sampaio, 2017; Morceiro, 2016; Nassif, 2008); seja pela tipologia de grupos industriais baseada em commodities agrícolas processadas, indústria tradicional, commodities industriais, indústria inovativa e outras (Vital da Costa e Neves, 2016).

- A regressão produtiva se combina, no Brasil, com elevada heterogeneidade de comportamentos entre os ramos de atividades e com redução ou baixo crescimento de produtividade média do trabalho (VTI/PO ou VBP/PO). Comprovam isso os trabalhos organizados por De Negri e Cavalcante (2014 e 2015) com avaliaçóes sobre a produtividade geral e setorial da economia brasileira, cobrindo, grosso modo, o período entre 2000 e 2013. Apontou-se amplamente fraca evolução dos níveis de produtividade quando comparados com aqueles apresentados por diversos outros países e também com relação à fronteira tecnológica (os Estados Unidos). Em outra perspectiva, avaliando a produtividade geral da indústria brasileira no período compreendido entre 1996 e 2015, medida pela relação VTI/População Ocupada, Monteiro Neto e Silva (2018) evidenciaram fraca evolução com o índice $100=1996$ atingindo o valor de 98 em 2015 . Regionalmente, esses autores verificaram também baixa produtividade associada à elevada heterogeneidade setorial e regional, isto é, mesmos ramos de atividades com elevados diferenciais de produtividade do trabalho em regióes distintas. No período de 1996 a 2015, a taxa de crescimento da produtividade para a indústria 
total (extrativa e transformação) nas regióes foi, respectivamente, para Norte, Nordeste, Sudeste, Sul e Centro-Oeste, de $-1,8 \%, 0,3 \%,-0,1 \%, 0,0 \%$ e 1,3\%. Por sua vez, a performance observada na indústria de transformação, no mesmo período, foi ainda pior para as mesmas regióes: a saber, respectivamente, $-1,6 \%$, $0,2 \%,-0,6 \%,-0,1 \%$ e $1,3 \%$.

- $\mathrm{O}$ debate em alguns círculos acadêmicos sobre a ideia de o Brasil ser uma economia fechada revela que as inúmeras e sucessivas medidas de política econômica implementadas nas últimas duas décadas, pelo menos, relacionadas com abertura comercial e financeira, diminuição de embaraços ao comércio exterior, facilitaçôes tarifárias, bem como uma política cambial favorável à integração a cadeias globais, resultaram mais em ampliaçáo da capacidade importadora e menos do potencial exportador nacional. Com sua estrutura produtiva fortemente assentada em empresas transnacionais (ETNs) nos ramos mais intensivos em capital e tecnologia, o Brasil tem ficado na dependência de decisóes das matrizes (nos países desenvolvidos) dessas empresas quanto ao papel do país na estrutura produtiva das cadeias globais. O que tem acontecido é uma ampliação do comércio internacional brasileiro por meio preponderante do atrelamento de importaçóes às cadeias de valor. A capacidade exportadora relacionada com bens de elevado valor agregado e/ou alto conteúdo tecnológico do país simplesmente não foi corretamente ativada no período. Pelo contrário, as exportaçốes que se ampliaram foram as de commodities agrícolas e minerais.

- A heterogeneidade regional do desenvolvimento como característica dominante. Exaurida a força dos dois vetores predominantes de crescimento nas regióes depois de 2015 - a demanda internacional por commodities e as políticas governamentais de transferência de rendas a famílias pobres e de crédito público -, as economias regionais já apresentam retração de seus mercados internos, desemprego e queda das receitas fiscais. Nesse quadro recessivo e de indeterminaçáo da capacidade de crescimento, os elementos estruturais que pautam o debate sobre a dinâmica produtiva retornam ao rol de preocupaçóes nacionais. Mesmo em regióes que apresentaram elevado crescimento econômico, a estrutura produtiva continua lastreada em ramos de atividades ligados a recursos naturais e na disponibilidade de mão de obra, como são os casos do Norte, Nordeste e Centro-oeste. Como já comentado anteriormente, a produtividade geral em cada economia regional teve pouco crescimento no período que cobre os anos de 1995 a 2015, com o predomínio de intensas variaçôes desse indicador entre as regióes.

- A longa e precária reestruturaçáo produtiva no Brasil. Possivelmente, esse deve ser o principal recado provocado pela temática do presente dossiê, razão pela qual merece ser devidamente registrado. Desde, pelo menos, a crise dos anos 1980, passando pelas reformas macroeconômicas - financeiras, produtivas e comerciais - dos anos 1990 e pelo crescimento nos anos entre 2005 e 2014, a reestruturação tecnológica do parque produtivo nacional vem se dando em lenta agonia. Suas características mais distintivas têm sido a perda da centralidade dos setores industriais na dinâmica produtiva, a redução da capacidade exportadora de bens de alto valor agregado, a dependência da demanda externa por commodities agroindustriais, a incapacidade de criação e consolidaçáo de um núcleo de desenvolvimento tecnológico para promover a renovação do sistema produtivo. 
- A longa e fraca trajetória de redução das disparidades regionais. Vários são os indicadores econômicos e sociais que apresentam a existência de um movimento de convergência regional. Contudo, as disparidades de renda per capita permanecem elevadas e sua perspectiva de aproximação, segundo alguns cálculos e prediçôes, é de décadas à frente (quatro ou cinco, na melhor das hipóteses). Ao lado desse reconhecimento das impossibilidades, o fator mais elucidativo é o de que a expansão econômica das regiôes de menor desenvolvimento continua a ser determinada pelos impulsos ora da economia regional de maior centralidade - o Sudeste -, ora dos ventos que sopram da demanda mundial por recursos naturais do país. São regiôes, portanto, que permanecem estruturalmente pouco dinâmicas. Seu futuro imediato para a evoluçáo produtiva tende a ser o retraso relativo na presença de taxas positivas de expansão.

Dos consensos apresentados decorrem algumas sugestóes para uma agenda de pesquisa sobre o desenvolvimento territorial brasileiro e seus desafios presentes, conforme se vê na sequência.

- Primeiro, reconhecer que na última década e meia um conjunto de açóes governamentais intencionou alterar trajetórias territoriais consolidadas. Nem sempre os acertos foram reconhecidos, porém houve algum êxito. As políticas sociais tiveram impactos positivos sobre a renda das regiōes mais pobres, dinamizando economias locais, notadamente nas regiốes Norte e Nordeste. A ampliação do crédito público para o investimento privado, realizada pelo BNDES e pelos bancos regionais, foi capaz de alimentar negócios industriais, terciários e agrícolas (incluindo aqui o Pronaf, Programa Nacional de Fortalecimento da Agricultura Familiar) em favor de regióes-alvo das políticas regionais. Neste sentido, em linha com as observaçôes sobre territórios impactados por açôes governamentais propostas por Brandão (artigo 2), uma avaliaçáo mais atenta das açóes que deram certo, de seu alcance e suas consequências, precisa ser tomada em consideração visando a sua continuidade e/ou reformulação, quando necessário. Por exemplo, no debate sobre a desindustrialização brasileira pouco se atrela esse resultado insatisfatório aos baixos estímulos em termos de financiamento público para a atividade em foco. Na verdade, segundo relatórios oficiais dos bancos públicos, além de BNDES e outros, as atividades que mais receberam recursos das fontes bancárias públicas foram aqueles pertencentes ao setor terciário e à agropecuária. Os incentivos de crédito, portanto, foram concedidos pela política bancária oficial, a despeito de suas intençôes de reverter o quadro de perda de relevância da indús-

1 Para uma leitura atualizada de debates e proposições para alteração em políticas para o desenvolvimento regional, ver o texto "Desenvolvimento territorial e crescimento inclusivo: avaliação de políticas e propostas de aperfeiçoamento", presente em documento recente do Ipea intitulado Desafios da nação-2018. tria, para setores e ramos produtivos de mais baixa produtividade econômica ${ }^{1}$.

- Ausentes das discussóes neste dossiê foram as reflexôes sobre a rede de cidades e seu papel para o desenvolvimento regional. Apenas indiretamente esse tema foi tratado no âmbito do estudo sobre a macrometrópole paulista (artigo 5) e no artigo de Moraes e Steinberger (artigo 3), sobre experiências de desconcentração econômica na escala intraestadual. Muito já se pesquisou sobre a rede de cidades e seu papel na reestruturação do território, no entanto, um balanço de suas transformações mais recentes, em par com a preocupação de avaliação dos porquês da desindustrialização, ainda está para ser feito. Sabe-se que a ampliação das rendas dos mais pobres resultou em ampliação de mercados consumidores em cidades médias com funçôes estratégicas na rede de cidades, entretanto, não se sabe qual 
o poder multiplicador existente, nem se têm notícias sobre estudos comparados de crescimento em cidades médias com tamanhos e funções similares estimulados pelos efeitos de expansão das rendas dos mais pobres. Adicionalmente, indagase: como se expandiu a rede de cidades da regiáo Centro-Oeste estimulada pelo boom de commodities e quais as interaçóes destas com as demais redes regionais brasileiras? E, ainda, como se comportou a rede de cidades em regióes consolidadas como as do Sul e Sudeste do país ao longo do ciclo expansivo recente? Em um plano mais geral, uma visão unificadora sobre o padrão de comportamento das cidades médias e das formas de reestruturação produtiva em curso torna-se elemento crucial para o desenho de políticas públicas².

- Tem sido uma orientação predominante na política de desenvolvimento produtivo e regional brasileira a ideia de apoio, estímulo, criação de facilidades e externalidades para o capital físico (fábricas, indústrias, rodovias etc.). Na contramão dessa vertente, pouca atençáo foi dada ao apoio e desenvolvimento da mão de obra ou capital humano. Nas últimas décadas, entretanto, alguns passos foram dados para a construção de uma trajetória diferente no país por meio da expansão e da interiorização da infraestrutura de extensão e de pesquisa. Alguns estudos (como o de Vieira, 2017) registraram tais apostas, embora este siga como um tema a demandar mais pesquisa. Há um duplo interesse nessa dimensão do desenvolvimento: uma é a do papel que as cidades médias recebedoras de infraestruturas de conhecimento passam a ter a partir de entáo sobre sua regiáo de influência e a outra é a da necessária articulação a ser criada entre esses centros de conhecimento e pesquisa e o tecido produtivo (empresas, famílias e governos) existente. A renovação produtiva em direção a atividades de mais elevada produtividade depende das interaçóes que vierem a ser criadas nos ambientes de criaçáo e circulação de ideias.

Espera-se que este dossiê temático estimule a comunidade acadêmica e os formuladores de políticas públicas a recuperar a centralidade do tema em suas agendas de trabalho e na agenda governamental. Tal resgate poderá contribuir para novas formulaçôes de políticas públicas capazes de fomentar uma nova pauta para o desenvolvimento regional, diante de um país continental cada vez mais heterogêneo.

\section{REFERÊNCIAS}

ALVES, Adriana Melo. Políticas de desenvolvimento regional e rede de cidades no semiárido: concentração, polarização e fragmentação. Tese de doutorado. Departamento de Geografia. Universidade de Brasília. 2017.

AREND, Marcelo et al. Mudança estrutural redutora da produtividade: o falling behind brasileiro. Anais da Anpec. Foz do Iguaçu. 2016.

BONELLI, Regis; PESSOA, Samuel; MATOS, Silvia. Desindustrialização no Brasil: fatos e interpretação. In: BACHA, Edmar; DE BOLLE, Monica B. (Orgs.). O futuro da indústria no Brasil - desindustrialização em debate. Cap. 2. Rio de Janeiro. Civilização Brasileira. 2013.

CANO, Wilson. A desindustrialização no Brasil. Revista Economia e Sociedade, Campinas, SP. V. 21, p. 831-51, 2012.
2 A tese de doutorado de Adriana Melo Alves, Políticas de desenvolvimento regional e rede de cidades no semiárido: concentração, polarização e fragmentação, traz aportes significativos para o caso de cidades intermediárias no semiárido do Nordeste brasileiro. Reúne evidências de mudanças infraestruturais de monta na região e aponta para avanços na competitividade e na atração de investimentos nas cidades investigadas.

Aristides Monteiro Neto é economista com Doutorado em Economia Aplicada pelo IE/UNICAMP (2005) e Mestrado em Economia pelo PIMES/UFPE (1995). Pesquisador Sênior do IPEA e especialista em Desenvolvimento Econômico, Economia Regional e Políticas Públicas. Atualmente é Diretor de Estudos Regionais, Urbanos e Ambientais do IPEA.

E-mail: aristides.monteiro@ ipea.gov.br

ORCID: 0000-0002-09303062

Rovena Negreiros possui graduação em Direito pela Universidade Federal do Espírito Santo (1981), mestrado em Direito pela Universidade Federal de Santa Catarina (1988) e Especialista em Poíticas Públicas pelo IE- Unicamp(1993). Foi Professora de graduação e pós graduação do Instituto de Economia da Unicamp e Pesquisadora no Núcleo de Economia Social e UrbanaNesur-IE Unicamp. Foi Diretora-adjunta de Análise e Disseminação de Informações da Fundação SEADE e Diretora-Presidente da Emplasa. Atua principalmente no tema da Gestão Metropolitana Desenvolvimento Regional.

E-mail: rovena.negreiros@ terra.com.br

ORCID: 0000-0002-54146414

Artigo recebido em 13 de março de 2019 e aprovado para publicação em 01 de abril de 2019.

Artigo licenciado sob Licença Creative Commons (CC-BY). 
D OS S I E : PARA D I G A S TÉ C N I C O-E C O N Ô M I C O S...

DE NEGRI, Fernanda; CAVALCANTE, Luiz R. Produtividade no Brasil-desempenho e determinantes. V. 1. Brasília, DF: Ipea. 2014.

Ipea. 2015

Produtividade no Brasil-desempenho e determinantes. V. 2. Brasília, DF:

FURTADO, Celso. Desenvolvimento e subdesenvolvimento. Rio de Janeiro: Fundo de Cultura, 1961.

GALA, Paulo. Complexidade econômica: uma nova perspectiva para entender a antiga questão da riqueza das naçóes. São Paulo: Contraponto, 2017.

GALEANO, Edileuza; FEIJÓ, Carmen. A estagnação da produtividade do trabalho na indústria brasileira nos anos 1996-2007: análise nacional, regional e setorial. Nova Economia, v. 1, n. 23, p. 9-50, 2013.

IPEA. Desafios da nação. V. 2. Brasília, DF. 2018. Disponível em: <http://www.ipea.gov. br/portal/images/stories/PDFs/livros/livros/181218_desafios_da_nacao_vol2.pdf>. Acesso em março de 2019.

KALDOR, Nicholas. Causes of the slow rate of economic growth of The United Kingdom. London: Cambridge University Press. 1966.

. The case for regional policies. Scottish Journal of Political Economy, v. 17, n. 3, p. 337-48. 1970.

KUZNETS, Simon. Economic growth of nations: total output and production structure. Cambridge: Harvard University Press. 1971.

LEWIS, W. A. Economic development with unlimited supplies of labour. The Manchester School, v. 22, n. 2, p. 139-91. 1954.

MONTEIRO NETO, A.; SILVA, Raphael de O. Desconcentração territorial e reestruturação regressiva da indústria no Brasil: padróes e ritmos. Texto para discussão n. 2402. Brasília, DF: Ipea. 2018.

MORCEIRO, Paulo César. Vazamento de demanda setorial e competitividade da indústria de transformação brasileira. Texto para discussão n. 12. Nereus. FEA-USP. São Paulo. 2016.

MYRDAL, Gunnar. Economic theory and underdeveloped regions. London: Duckworth. First Edition. 1957.

PREBISCH, Raúl. El desarrollo económico de la América Latina y algunos de sus principales problemas. Desarrollo Econômico, v. 26, n. 103, p. 479-502. 1949.

SAMPAIO, Daniel. Desindustrialização e estruturas produtivas regionais no Brasil. Tese de doutorado. Instituto de Economia, Unicamp. Campinas, SP. 2015.

SARTI, Fernando; HIRATUKA, Célio. Desempenho recente da indústria brasileira no contexto de mudanças estruturais domésticas e globais. Texto para discussão n. 290. Unicamp. Campinas, SP. 2017.

VIEIRA, Danilo. Evolução do ensino superior brasileiro em período recente: novas perspectivas para o desenvolvimento regional? In: MONTEIRO, Aristides et al (Orgs.). Desenvolvimento regional no Brasil-politicas, estratégicas e perspectivas. Cap. 9.Brasília, DF: Ipea. 2017.

VITAL DA COSTA, K. G.; NEVES, Fábio Freitas. Padróes de interdependência setorial da estrutura produtiva brasileira entre 2000 e 2015: uma análise insumo-produto a partir da decomposição da matriz de Leontief. Encontro Anual de Economia Política. São Bernardo do Campo, SP. 2016. 